\title{
TU/e Emonowe

\section{Investigations on the phase formations, properties and single crystal growth in the high-Tc superconducting $\mathrm{Ca}-\mathrm{Sr}-\mathrm{Bi}-\mathrm{Cu}-\mathrm{O}$ system}

\author{
Citation for published version (APA): \\ Huang, Y. K., Kadowaki, K., Menken, M. J. V., Li, J. N., Bakker, K., Menovsky, A. A., Franse, J. J. M., Bastin, G. \\ F., \& Heijligers, H. J. M. (1988). Investigations on the phase formations, properties and single crystal growth in \\ the high-Tc superconducting Ca-Sr-Bi-Cu-O system. Physica C : Superconductivity, 152(5), 431-437. \\ https://doi.org/10.1016/0921-4534(88)90048-2
}

DOI:

10.1016/0921-4534(88)90048-2

Document status and date:

Published: 01/01/1988

\section{Document Version:}

Publisher's PDF, also known as Version of Record (includes final page, issue and volume numbers)

\section{Please check the document version of this publication:}

- A submitted manuscript is the version of the article upon submission and before peer-review. There can be important differences between the submitted version and the official published version of record. People interested in the research are advised to contact the author for the final version of the publication, or visit the DOI to the publisher's website.

- The final author version and the galley proof are versions of the publication after peer review.

- The final published version features the final layout of the paper including the volume, issue and page numbers.

Link to publication

\footnotetext{
General rights

- You may freely distribute the URL identifying the publication in the public portal. follow below link for the End User Agreement:

www.tue.nl/taverne

\section{Take down policy}

If you believe that this document breaches copyright please contact us at:

openaccess@tue.nl

providing details and we will investigate your claim.
}

Copyright and moral rights for the publications made accessible in the public portal are retained by the authors and/or other copyright owners and it is a condition of accessing publications that users recognise and abide by the legal requirements associated with these rights.

- Users may download and print one copy of any publication from the public portal for the purpose of private study or research.

- You may not further distribute the material or use it for any profit-making activity or commercial gain

If the publication is distributed under the terms of Article $25 \mathrm{fa}$ of the Dutch Copyright Act, indicated by the "Taverne" license above, please 


\title{
INVESTIGATIONS ON THE PHASE FORMATIONS, PROPERTIES

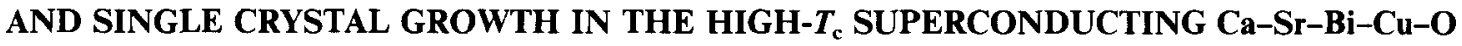 SYSTEM
}

\author{
Y.K. HUANG ' , K. KADOWAKI ', M.J.V. MENKEN ', J.N. LI ${ }^{1}$, K. BAKKER ${ }^{\text {, }}$ \\ A.A. MENOVSKY ', J.J.M. FRANSE ', G.F. BASTIN ${ }^{2}$, H.J.M. HEIJLIGERS ${ }^{2}$, H. BARTEN ${ }^{3}$, \\ J. VAN DEN BERG ${ }^{4}$, R.A.ZACHER ${ }^{4}$ and H.W. ZANDBERGEN ${ }^{5}$ \\ Natuurkundig Laboratorium, University of Amsterdam, Valckenierstraat 65, 1018 XE Amsterdam, The Netherlands \\ 2 Laboratory for Physical Chemistry, Centre for Technical Ceramics, University of Technology, Eindhoven, The Netherlands \\ 3 Joint Laboratories of the Dutch Electricity Supply Companies, Arnhem. The Netherlands \\ 4 Kamerlingh Onnes Laboratorium, University of Leiden. The Netherlands \\ 5 Gorlaeus Laboratorium, University of Leiden, The Netherlands
}

Received 13 May 1988

\begin{abstract}
We have performed investigations on the $\mathrm{Ca}-\mathrm{Sr}-\mathrm{Bi}-\mathrm{Cu}-\mathrm{O}$ system with respect to high- $T_{\mathrm{c}}$ superconductivity and structural properties. It is shown that there are two high- $T_{\mathrm{c}}$ superconducting phases in the system, i.e. a $110 \mathrm{~K}$ and an $85 \mathrm{~K}$ phase. The $85 \mathrm{~K}$ phase has a body-centred tetragonal structure with a stoichiometry of $\mathrm{CaSr}_{2} \mathrm{Bi}_{2} \mathrm{Cu}_{2} \mathrm{O}_{8}$. The $110 \mathrm{~K}$ phase is closely related to the $85 \mathrm{~K}$ phase. It is formed only in a very narrow temperature range and easily deteriorates to the phase with the lower $T_{\mathrm{c}}$ by quenching. Although some samples show a large diamagnetic signal at $110 \mathrm{~K}$ in ac-susceptibility measurements, there is still evidence of the presence of the $85 \mathrm{~K}$ phase. X-ray diffraction studies, especially in the low-angle region, show a structural relation between these two superconducting phases. The procedures of the preparation and the characterization of the $85 \mathrm{~K}$ and $110 \mathrm{~K}$ polycrystalline superconducting phases as well as the single crystal growth of the $85 \mathrm{~K}$ superconducting phase are described.
\end{abstract}

\section{Introduction}

Since the discovery of high- $T_{\mathrm{c}}$ superconductivity around $110 \mathrm{~K}$ in the multiphase $\mathrm{Ca}-\mathrm{Sr}-\mathrm{Bi}-\mathrm{Cu}-\mathrm{O}$ system by Maeda et al. [1], much effort has been concentrated on the identification and characterization of the phases responsible for the high- $T_{\mathrm{c}}$ superconductivity $[2,3]$. Single crystal growth of the $85 \mathrm{~K}$ phase and its composition, structure and physical properties have also been reported [4-6]. At the early stage of our investigations [7], we have reported results on the high resolution electron microscopy of samples with the nominal composition of $\mathrm{CaSrBiCu} \mathrm{O}_{2}$. These samples exhibit nearly zero resistance at $107 \mathrm{~K}$. At least two major phases in the sample were found with the approximate composition ratio of $\mathrm{Ca}: \mathrm{Sr}: \mathrm{Bi}: \mathrm{Cu}$ equal to $0.8: 1.7: 2: 2$ (corresponding to the $c$-axis about $31 \AA$ ) and
$1.2: 1.4: 2: 3$ (corresponding to the $c$-axis about 37 $\AA$ ). The $c$-axis in the latter phase is about $6 \AA$ longer than that of the former one. Consequently, it is proposed that the latter phase is formed by inserting two additional atomic layers, probably $\mathrm{Ca}$ and $\mathrm{CuO}_{2}$ layers, into the $31 \AA$ phase, and may be responsible for the $110 \mathrm{~K}$ transition. Similar results were found in the $\mathrm{Ca}-\mathrm{Ba}-\mathrm{Tl}-\mathrm{Cu}-\mathrm{O}$ system, which also exhibits two superconducting phases [8].

In this paper we mainly describe our preparation methods and characterizations of the $85 \mathrm{~K}$ and 110 $\mathrm{K}$ superconducting phases in the $\mathrm{Ca}-\mathrm{Sr}-\mathrm{Bi}-\mathrm{Cu}-\mathrm{O}$ system from the nominal starting compositions 1112 , 1222,2223 . The single crystal growth and the characterization of the $85 \mathrm{~K}$ phase are also presented.

Samples were analysed by DTA, TGA, electron microprobe, $\mathrm{X}$-ray and electron microscopy. Superconductivity was characterized by ac-susceptibility 
and four-point ac- and dc-resistivity measurements. The temperature dependence of the magnetization in a low magnetic field was measured and the Meissner effect was determined with a SQUID magnetometer for some samples.

\section{Sample preparation}

All samples were prepared by the standard solid state reaction method similar to that used for the preparation of $\mathrm{YBa}_{2} \mathrm{Cu}_{3} \mathrm{O}_{7}$. The starting ingredients $\left(\mathrm{CaCO}_{3}, \mathrm{SrCO}_{3}, \mathrm{Bi}_{2} \mathrm{O}_{3}\right.$ and $\mathrm{CuO}$, Johnson Matthey, Specpure) were well-mixed, pressed into pellets and heated in an alumina crucible for 15 hours. The heating temperature is varied from 800 to $880^{\circ} \mathrm{C}$, according to the different compositions of the samples. After milling, the powder products were pressed into pellets again and subsequently heated at the same temperature. This procedure may be repeated to ensure the homogeneity. The final products were further processed using different heat-treatments and quenching procedures, as described below. A large number of samples with various nominal compositions we prepared and examined. Here we describe the methods of the preparation for those samples with the nominal starting composition 1112, 1222 and 2223 , which show the highest superconducting transition temperature.

\subsection{2 starting composition}

Samples with this nominal composition showed the highest superconducting transition temperature at $110 \mathrm{~K}$ among the samples measured so far. One of the experimental procedures was as follows. The pellets from the reacted products as described above were annealed at $850^{\circ} \mathrm{C}$ for 22 hours, and quenched into liquid nitrogen, then pulverized and pressed into pellets again. The pellets were sintered at $880^{\circ} \mathrm{C}$ for 60 hours and quenched into liquid nitrogen. As a final procedure the samples were annealed at $890^{\circ} \mathrm{C}$ for 20 minutes, then at $880^{\circ} \mathrm{C}$ for 9 hours and furnace-cooled to room temperature. The result of the ac-susceptibility measurement for this sample is shown in fig. 1 (open circles). The amplitude of the diamagnetic signal is normalized by the weight of the sample. From fig. 1, two step-wise transitions are

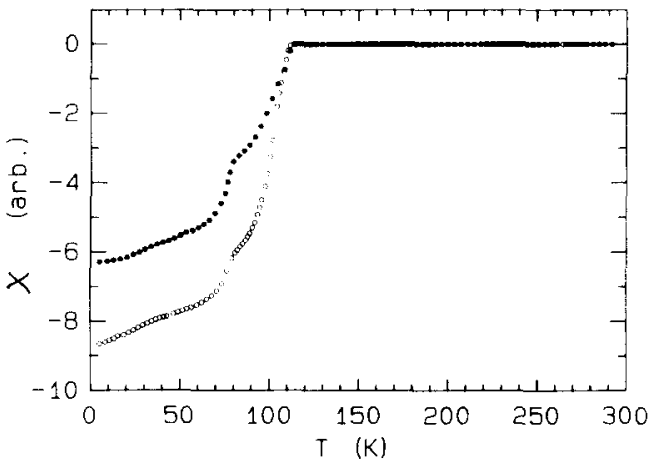

Fig. 1. Temperature dependences of ac-susceptibility for samples of starting composition $1112(0)$ and $2223(\bullet)$.

clearly seen at $110 \mathrm{~K}$ and at $80 \mathrm{~K}$, indicating two different superconducting phases. It is noted that the amplitude of the diamagnetic signal for the $110 \mathrm{~K}$ transition is much larger than that for the $85 \mathrm{~K}$ transition and that the ratio of the diamagnetic signal between these two phases is not influenced by the pulverization of the sample. These facts imply that the $110 \mathrm{~K}$ phase in the sample is a major superconducting phase and has bulk superconductivity.

The temperature dependence of the magnetization of the sample was measured with a SQUID magnetometer in a magnetic field of $10 \mathrm{G}$. Two distinct jumps in the magnetization were observed, as seen in fig. 2. The first onset of diamagnetism occurs at $106 \mathrm{~K}$ and the second at $77 \mathrm{~K}$. These steps clearly

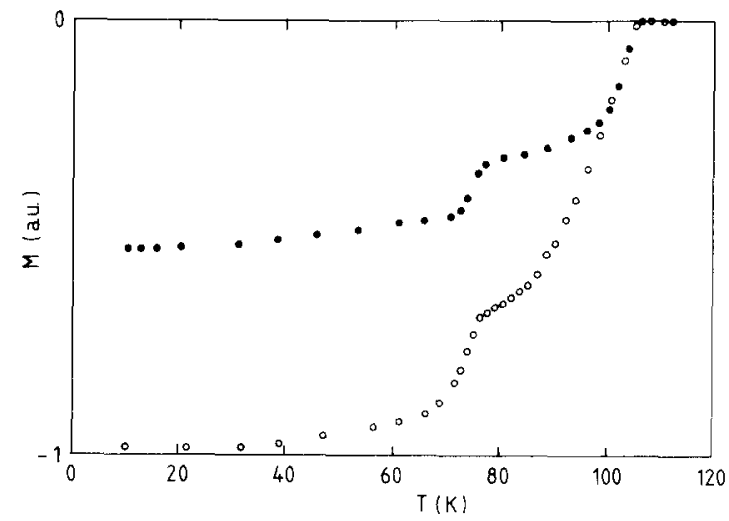

Fig. 2. Temperature dependence of the magnetization of the sample with starting composition 1112 measured by a SQUID magnetometer in a magnetic field of $10 \mathrm{G}(\bullet)$ and without magnetic field cooling $(\mathrm{O})$. 
correspond to the presence of two superconducting phases in the sample, as previously seen in the acsusceptibility measurements. The Meissner effect is about $50 \%$ of the total shielding effect for both phases. About $65 \%$ of the total Meissner effect is attributed to the $110 \mathrm{~K}$ phase in this case, indicating again the bulk nature of superconductivity.

Several samples which were heated only $880^{\circ} \mathrm{C}$ for 3 or 4 days and were furnace-cooled also show a large diamagnetic signal with the onset temperature around $110 \mathrm{~K}$. It is noted that in all cases a mixture of the $80 \mathrm{~K}$ and the $110 \mathrm{~K}$ phases is present in the sample.

We have recognized that the $110 \mathrm{~K}$ superconducting transition can easily be suppressed to 85-95 $\mathrm{K}$ by quenching the sample into liquid nitrogen after a short time annealing at any temperature between $850^{\circ} \mathrm{C}$ and $880^{\circ} \mathrm{C}$. The quenching effect on ac-susceptibility of the sample is illustrated in fig. 3 .

The samples which were not annealed at $880^{\circ} \mathrm{C}$ for a long time, show a $T_{c}$ near or below $80 \mathrm{~K}$. It is observed that the $T_{\mathrm{c}}$ of these samples can be enhanced to $85-95 \mathrm{~K}$ by a short time heating at $840^{\circ} \mathrm{C}$ to $880^{\circ} \mathrm{C}$ and then by quenching into liquid nitrogen.

It was found that 1112 samples have no phase transitions below $880^{\circ} \mathrm{C}$ by DTA, which measures were performed in air with a heating rate of $10^{\circ} \mathrm{C} /$ min. An endothermic peak starts at $880^{\circ} \mathrm{C}$, followed by two other peaks at 930 and $970^{\circ} \mathrm{C}$, as seen in fig. 4. These peaks indicate three different melting stages.

The TGA experiments show that there is no weight

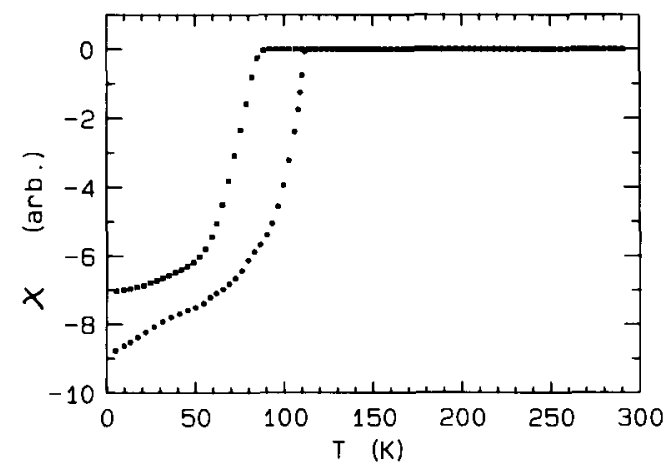

Fig. 3. The quenching effect on the ac-susceptibility of the sample with starting composition 1112 . Solid circles (O) indicate the results before quenching. The sample shows the onset of $T_{\mathrm{c}}$ at $110 \mathrm{~K}$. After quenching the sample from $880^{\circ} \mathrm{C}$ into liquid nitrogen, the onset of $T_{\mathrm{c}}$ is suppressed to $85 \mathrm{~K}(\mathbf{D})$. Te amplitude of the signal after quenching is reduced.

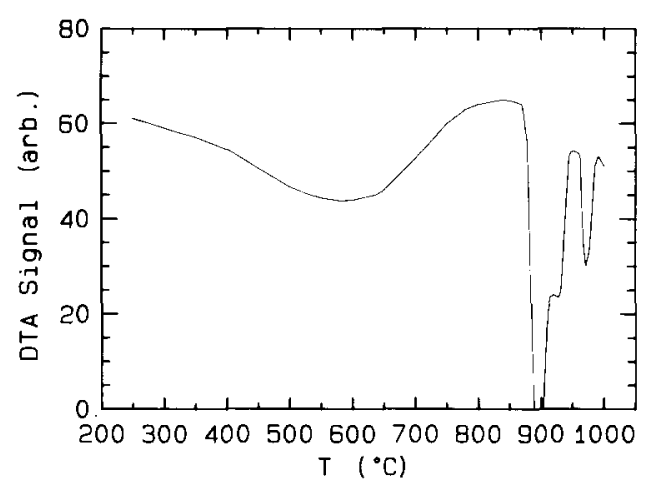

Fig. 4. Chart of the differential thermal analysis in air for the sample with starting composition 1112 . The heating rate was $10^{\circ} \mathrm{C} / \mathrm{min}$.

change in the sample up to $880^{\circ} \mathrm{C}$, which is in contrast to the case of the $\mathrm{YBa}_{2} \mathrm{Cu}_{3} \mathrm{O}_{7}$ system.

\subsection{2 starting composition}

According to Zandbergen et al. [7], the composition of $\mathrm{CaSr}_{2} \mathrm{Bi}_{2} \mathrm{Cu}_{2} \mathrm{O}_{x}$ corresponds to the $85 \mathrm{~K}$ phase. So far we have not observed the $110 \mathrm{~K}$ transition in the samples of this composition. We have obtained this $85 \mathrm{~K}$ phase as follows. The samples were reacted at $820^{\circ} \mathrm{C}$ for 15 hours. The already reacted samples were heated again at $880^{\circ} \mathrm{C}$ for 60 hours with intermediate milling and pressing into pellets and were finally furnace-cooled.

Superconductivity at $85 \mathrm{~K}$ is also obtained by quenching the samples into liquid nitrogen from $850^{\circ} \mathrm{C}$ without a long time heat treatment at $880^{\circ} \mathrm{C}$.

In general, the $85 \mathrm{~K}$ phase is easily obtained in a wide range of the starting compositions. However, a homogeneous single phase, starting from this stoichiometric composition, has not been achieved yet. Grains with a wide range of $\mathrm{Ca}: \mathrm{Sr}: \mathrm{Bi}: \mathrm{Cu}$ composition ratios, such as $1: 1.8: 1.7: 1.9$ and $1: 1.8: 1.3: 1.6:$, were found in the electron microprobe analyses.

\subsection{3 starting composition}

Although the composition of $\mathrm{Ca}_{2} \mathrm{Sr}_{2} \mathrm{Bi}_{2} \mathrm{Cu}_{3} \mathrm{O}_{x}$ is suggested by Zandbergen et al. [7] to be the phase responsible for the superconductivity at $110 \mathrm{~K}$, we have not succeeded in obtaining the $110 \mathrm{~K}$ single 
phase in the samples with this starting composition. If samples are heated at $850^{\circ} \mathrm{C}$ for 20 hours and are furnace-cooled, the superconducting transition at $75-$ $80 \mathrm{~K}$ is found. The $\mathrm{X}$-ray powder diffraction pattern shows an almost single phase character as an $85 \mathrm{~K}$ phase (with the $c$-axis of $30.6 \AA$ ). By quenching the sample from $850^{\circ} \mathrm{C}$ into liquid nitrogen, the $T_{\mathrm{c}}$ is enhanced to about $90-95 \mathrm{~K}$. The X-ray diffraction pattern of the quenched sample shows almost the same pattern as before, only with a slight shift to higher angle in $2 \theta$ and with the intensity change of some peaks.

After heated at $880^{\circ} \mathrm{C}$ for a few days and furnacecooled, the samples show the $110 \mathrm{~K}$ superconducting transition. However, the lower $T_{\mathrm{c}}$ phase is always present together with the $110 \mathrm{~K}$ phase (shown in fig. 1), similar to the 1112 samples.

\section{Single crystal growth of the $85 \mathrm{~K}$ phase}

In the course of our investigations we have succeeded in growing single crystals of the $85 \mathrm{~K}$ superconducting phase by the following procedure. A mixture of the starting components of $\mathrm{CaCO}_{3}, \mathrm{SrCO}_{3}$, $\mathrm{Bi}_{2} \mathrm{O}_{3}$ and $\mathrm{CuO}$ (Johnson Matthey, Specpure) in the $\mathrm{Ca}: \mathrm{Sr}: \mathrm{Bi}: \mathrm{Cu}$ ratio of $1: 2: 2.5: 2.5$ was placed in an alumina crucible and heated at $890^{\circ} \mathrm{C}$ for several hours. The mixture was melted completely at this temperature. The molten sample was then cooled with a rate of $3^{\circ} \mathrm{C} / \mathrm{h}$ to $790^{\circ} \mathrm{C}$ and finally to $340^{\circ} \mathrm{C}$ with the rate of $30^{\circ} \mathrm{C} / \mathrm{h}$. The crucible was crushed and crystals were separated from the matrix. The platelike crystals, normally sitting at the center of the crucible, congregated together with some unknown phases. Some yellowish materials, which have a higher melting point, adhere to the wall of the crucible. The separated single crystals have typical dimensions of $0.5 \times 0.5 \times 0.01 \mathrm{~mm}^{3}$ and have a well developed lamellar structure with a metallic luster. A SEM picture of the single crystal is shown in fig. 5 .

Electron microprobe analyses show that the composition ratio of $\mathrm{Ca}: \mathrm{Sr}: \mathrm{Bi}: \mathrm{Cu}: \mathrm{O}$ in a platelike single crystal is about $0.89: 2.11: 2.10: 2: 9.44$, with less $\mathrm{Ca}$ and an excess of the $\mathrm{Sr}$ and $\mathrm{Bi}$ contents comparing to the stoichiometric ratio of 1222 .

The X-ray powder diffraction analyses of the col-

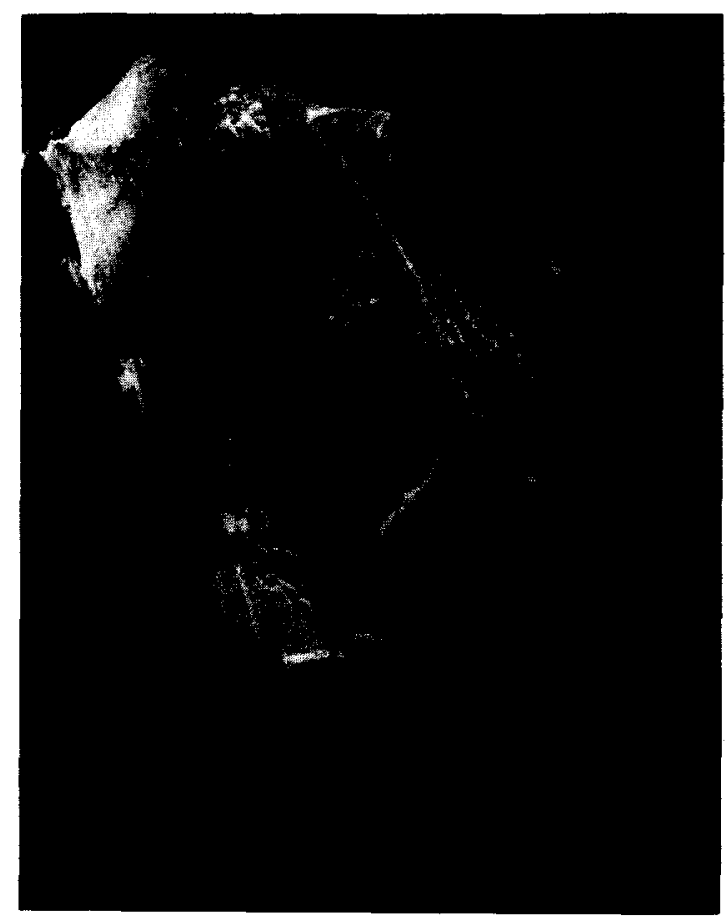

Fig. 5. Photograph of the $85 \mathrm{~K}$ single crystal taken by a scanning electron microscope. The scale in the picture represents $100 \mu \mathrm{m}$.

lection of single crystals show a body-centered tetragonal structure with lattice parameters of $3.843 \AA$ and $30.79 \AA$ for the $a$ - and $c$-axes, respectively.

The temperature dependence of the ac-susceptibility measured on an as-grown crystal is shown in fig. 6 . The onset of superconductivity is as high as 86 $\mathrm{K}$ and the total diamagnetic signal is larger than that of polycrystalline samples. In fig. 6 , a curve of the ac-

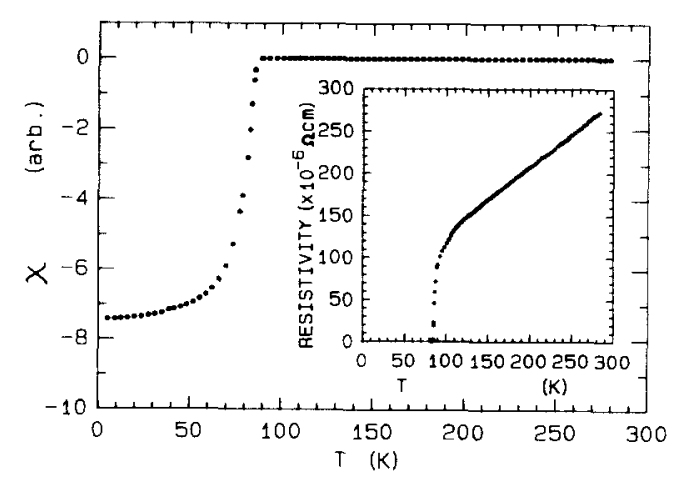

Fig. 6. Temperature dependences of the ac-susceptibility and acresistivity (inset) for the $85 \mathrm{~K}$ single crystal. 


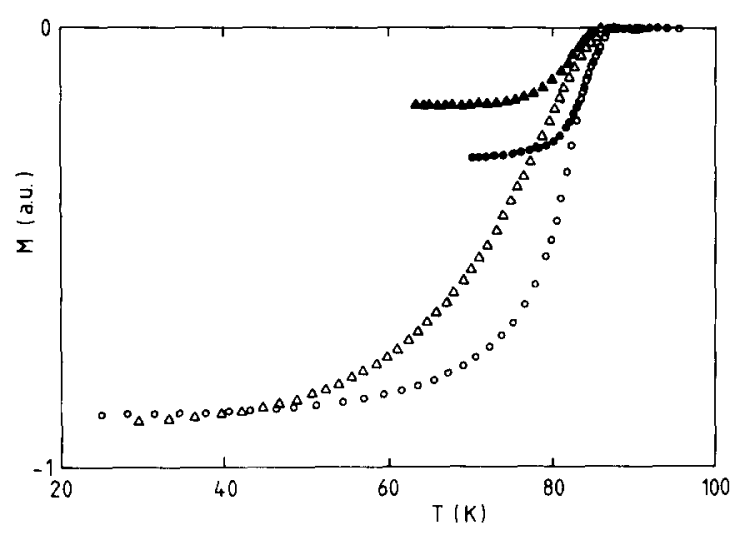

Fig. 7. Temperature dependences of the the magnetization for the $85 \mathrm{~K}$ single crystal by a SQUID magnetometer in magnetic fields of $3 \mathrm{G}$ (circles) and $10 \mathrm{G}$ (triangles). The open symbols indicate the magnetization due to the shielding effect, while the solid symbols show the Meissner effect in the corresponding magnetic fields. The magnetic field is applied parallel to the $c$ axis of the crystal.

resistivity of the single crystal is shown in the inset. In this case, a zero resistivity state $\left(<10^{-9} \Omega \mathrm{cm}\right)$ is reached at $82 \mathrm{~K}$.

A sharp onset of diamagnetism at $87 \mathrm{~K}$ is also found with a SQUID magnetometer, as shown in fig. 7. A plateau is reached around $50 \mathrm{~K}$. The Meissner effect is field dependent and is about $30 \%$ of the total shielding effect for $3 \mathrm{G}$ and about $25 \%$ for $10 \mathrm{G}$.

Besides the very thin platelike crystals, very thin whiskers with a typical length of several millimeters were found. It turned out by electron microprobe analyses to be a bismuth-rich phase with an approximate composition ratio of $\mathrm{Ca}: \mathrm{Sr}: \mathrm{Bi}: \mathrm{Cu}: \mathrm{O}$ equal to $0.96: 2.70: 4.40: 2: 14.85$.

\section{Discussion}

From the various experiments performed here, it is empirically recognized that the $110 \mathrm{~K}$ phase is formed only when the samples are annealed at a temperature very close to the first partial melting point for a long time. If the temperature exceeds the partial melting point, some unknown phases occur and the superconducting properties of the sample are severely degraded.

Without long time heating at $880^{\circ} \mathrm{C}$, the samples exhibit the $80-85 \mathrm{~K}$ superconducting transition only. The X-ray diffraction patterns for these samples show that the major phase has a body-centered tetragonal structure with lattice constants of $3.81-3.84 \AA$ and 30.5-30.8 $\AA$ for the $a$-and $c$-axes, respectively. As we mentioned above, the quenching procedure can enhance $T_{\mathrm{c}}$ to about $90 \mathrm{~K}$, while the X-ray pattern does

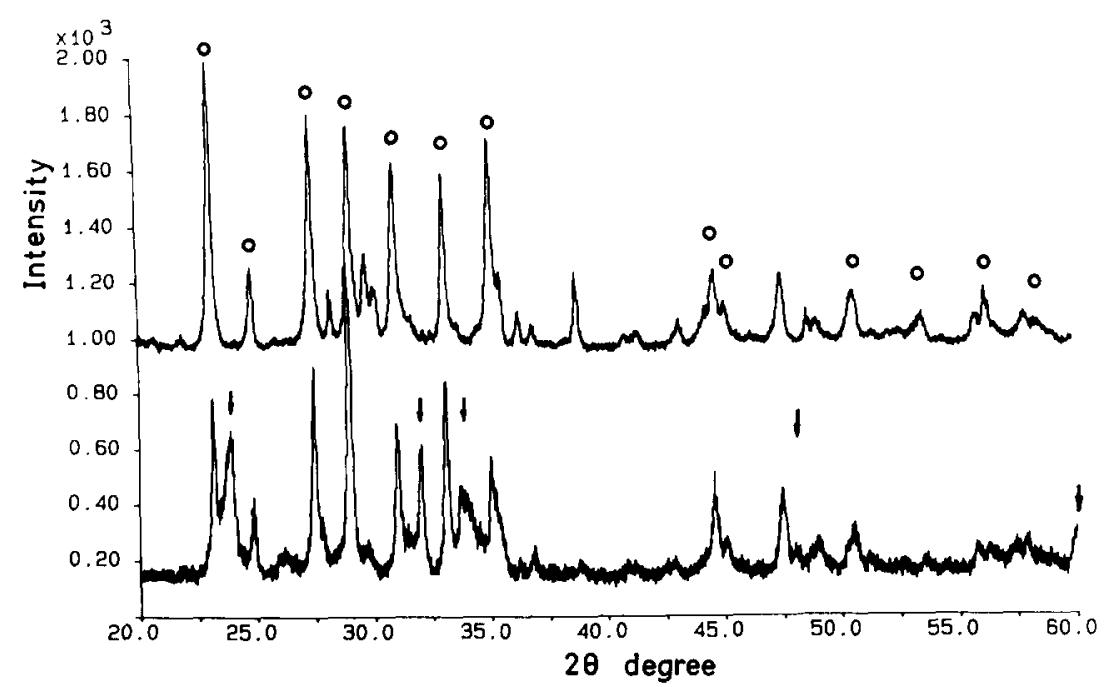

Fig. 8. X-ray powder diffraction patterns of the 1112 samples from 20 to 60 degrees in $2 \theta$ with $\mathrm{Cu} \mathrm{K} \alpha$ radiation. Top: the spectrum for the sample with $T_{\mathrm{c}}$ onset at $80 \mathrm{~K}$. The peaks marked by circles can be indexed by a body-centered tetragonal structure with $a=3.818 \AA$ and $c=30.64 \AA$. Bottom: the spectrum for the sample with $T_{\mathrm{c}}$ onset at $110 \mathrm{~K}$. Several new peaks are marked by arrows. 
not change drastically except for the intensities of some peaks. This fact suggests that there is no phase transition below the quenching temperature, which is consistent with the DTA results. The quenching effect on $T_{\mathrm{c}}$ as well as the wide range of lattice parameters in the different samples with different heat treatments may be due to the wide solubility range of some elements in this phase.

So far, we have not succeeded in obtaining the 110 $\mathrm{K}$ superconductor as a single phase. In all of our samples, the $110 \mathrm{~K}$ superconducting phase coexists with the $85 \mathrm{~K}$ phase. However, we have observed an interesting correlation between these two superconducting phases in the X-ray powder diffraction patterns. In fig. 8, the $\mathrm{X}$-ray powder diffraction patterns of two samples from 1112 starting composition with different heat treatments are presented. The spectrum shown in the top of the figure represents the samples with the onset of $T_{\mathrm{c}}$ at $80 \mathrm{~K}$. Most of the diffraction lines in this spectrum can reasonably be indexed to a body-centered tetragonal structure with lattice constants of $3.818 \AA$ and $30.64 \AA$ for the $a$ and $c$-axes, respectively. The rest of the weak diffraction lines indicate that some unknown minor phases exist in the sample. The spectrum shown in the bottom of the figure represents the samples with the superconducting onset at $110 \mathrm{~K}$. Comparing this spectrum with the upper one, several new peaks are found, as marked by arrows in fig. 8. These additional peaks can consistently be explained by assuming a body-centered tetragonal structure, similar to the $85 \mathrm{~K}$ phase, but with a longer $c$-axis of about 37 $\AA$.

In order to confirm the long periodicity of the 110 $\mathrm{K}$ phase, low-angle $\mathrm{X}$-ray powder diffraction analyses were performed between 4 and 6.5 degrees in $2 \theta$ ( $\mathrm{Cu} \mathrm{K} \alpha$ radiation ). The results are depicted in fig. 9. Comparing these spectra with the ac-susceptibility results, the correlation between the structural feature and the onset of the superconductivity is clearly seen. The $85 \mathrm{~K}$ single crystal described above shows a sharp peak at 5.81 degrees (see curve $A$ in fig. 9), which corresponds to the $(002)$ reflection of this phase with $c=30.79 \AA$. Curves B to E represent the low-angle Xray diffraction patterns for the samples with 1112 starting composition after different heat treatments. The samples which only show the $80 \mathrm{~K}$ transition have a similar pattern (curve $\mathrm{E}$ ) to the $85 \mathrm{~K}$ single

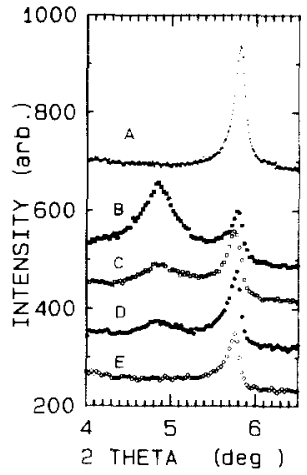

Fig. 9. Low-angle $\mathrm{X}$-ray powder diffraction spectra of the $85 \mathrm{~K}$ single crystal (curve $A$ ) as well as the 1112 samples with different heat treatments (curves from $B$ to $E$ ). A relatively broad peak around 4.85 degree in $2 \theta$ is closely related to the appearence of the $110 \mathrm{~K}$ phase. All samples with the onset of $T_{\mathrm{c}}$ at $110 \mathrm{~K}$ show this peak.

crystal. In curves $B$ to $D$ in fig. 9 , a new peak between 4.81 and 4.87 degrees in $2 \theta$, in addition to the (0.02) diffraction of the $85 \mathrm{~K}$ phase at about $5.5-$ 5.8 degrees, is observed. It is noted that the intensity ratio of the two peaks increases from curves $B$ to $D$, which is remarkably in correspondence to the fraction of the $110 \mathrm{~K}$ superconducting transition indicated by ac-susceptibility measurements. According to the high resolution electron microscopy results [7], the $110 \mathrm{~K}$ phase has a structure related to the $85 \mathrm{~K}$ phase and probably has a $c$-axis of about $37 \AA$. This implies that the new peak around 4.85 degrees may be due to the $(002)$ reflection of the $110 \mathrm{~K}$ phase. In fact, among the samples investigated, all samples which clearly show a $110 \mathrm{~K}$ transition have this peak, while all other samples which have only the $85 \mathrm{~K}$ transition do not show this peak. In general, this peak is broader than that of the $85 \mathrm{~K}$ phase, which means that the $110 \mathrm{~K}$ phase in the samples does not crystallize properly. It is highly probable that the $110 \mathrm{~K}$ phase is formed in a short-range ordered manner, either by decomposition of the $85 \mathrm{~K}$ phase at a temperature very close to the partial melting point or by an additional inclusion of $\mathrm{Ca}$ and $\mathrm{CuO}_{2}$ layers in the $85 \mathrm{~K}$ phase through a long distance diffusion. Difficulties of the preparation of the $110 \mathrm{~K}$ superconducting single phase may be due to the large unit cell, especially in the $c$-direction, which makes a long distance diffusion necessary, as well as due to 
the apparent slow thermodynamical kinetics of the $110 \mathrm{~K}$ phase formation.

\section{Acknowledgements}

We wish to acknowledge A.C. Moleman and W.F. Moolhuijzen for assistance in X-ray measurements. This work is part of the research program of the Centrum FOM-ALMOS (Amsterdam-Leiden Material Research Cooperation) and is supported by the "Stichting FOM" (Foundation for Fundamental Research on Matter) which is in turn sponsored by ZWO (Netherlands Organization for the Advancement of Pure Research).

\section{References}

[1] H. Maeda, Y. Tanaka, M. Fukutomi and T. Asano, Jpn. J. Appl. Phys. Lett. 27, no 2 (1988), to be published.

[2] J.M. Tarascon, Y. Le Page, P. Barboux, B.G. Bagley, L.H. Greene, W.R. McKinnon, G.W. Hull, M. Giroud and D.M. Hwang, preprint.

[3] T. Kajitani, K. Kusaba, M. Kikuchi, N. Kobayashi, Y. Syono, T.B. Williams and M. Hirabayashi, preprint.

[4] J.Z. Liu, G.W. Crabtree, L.E. Rehn, Urs Geiser, D.A. Young, W.K. Kwok, P.M. Baldo, Jack M. Williams and D.J. Lam, preprint.

[5] L.F. Schneemeyer, R.B. van Dover, S.H. Glarum, S.A. Sunshine, R.M. Fleming, B. Batlogg, T. Siegrist, J.H. Marshall, J.V. Waszczak and L.W. Rupp, Nature 332 (1988) 422.

[6] Y. Koike, T. Nakanomyo and T. Fukase, preprint.

[7] H.W. Zandbergen, Y.K. Huang, M.J.V. Menken, J.N. Li, K. Kadowaki, A.A. Menovsky, G. van Tendeloo and S. Amelinckx, Nature 332 (1988) 620.

[8] S.S.P. Parkin, V.Y. Lee, E.M. Engler, A.I. Nazzal, T.C. Huang, G. Gorman, R. Savoy and R. Beyers, preprint. 